\title{
Contents of Vol. 30, 1962
}

\section{Report}

Studies on Corrosion of Metals by Viscoplastic Substances.

III. On the Mechanism of Inhibitive Action of Silicate

Compounds in Viscoplastic Substances

$\left\{\begin{array}{l}\text { Minoru Izuyama } \\ \text { Yasumasa Hayakawa }\end{array}\right.$

Studies on Inhibitor of Aluminum in Alkaline Medium.

III. Aminophenols as an Inhibitor of Aluminum in

Alkaline Medium

(Katsuko Horiguchi

Yasuhiro Hagyuda
Seiji Takahashi E

Studies of Hydrogen-Chlorine Fuel Cell.

I. Basic Studies of the Hydrogen-Chlorine Fuel Cell at

Shiro Yoshizawa

Low Temperature

Fumio Hine

Zenichiro Takehara

E 10

Yasuhiro Kanaya

Regularities in the Osmotic Coefficients of Strong

Electrolytic Solutions

Makoto Moriyama

E 17

Kinetic Studies on Sulfidization of Metals....

Kazuo Fueki

Hirotsugu Ishibashi E 23

Kazuo Fueki

Hirotsugu Ishibashi E 71

Voltammetric Study of the Kolbe Reaction at a Rotating

Platinum Anode

M.J. Allen

W.G. Pierson

Studies on Ion Exchange Membranes.

XIX. Preparation of Ion Exchange Membranes Using

Methyl-Vinyl Ketone.

Yusuke Izumi

Yukio Mizutani

Shoichi Sasao

Yasuharu Onoue

Electrolytic Reduction of Uranyl Salt to Uranous Salt Without

Diaphragm

Keijiro Odo

Eiichi Ichikawa

E 57

On the Production of Persulfate by Electrolysis of Sodium

Sulfate Solution

Shiro Yoshizawa

Fundamental Studies on Lead Contamination of the

Electrodeposited Zinc Seitaro Fukushima

Contact Angle Measurement at Aluminum Surfaces B.A. Shenoi $\left\{\begin{array}{l}\text { S. Ramajayam } \\ \text { N. Rangarajan }\end{array}\right.$

Studies on the Mercuric Oxide Electrode.

I. Discharge Mechanism of the Mercuric Oxide Electrode $\cdots\left\{\begin{array}{l}\text { Shiro Yoshizawa } \\ \text { Zenichiro Takehara }\end{array} 93\right.$

Studies on Fuel Cells.

I. Studies on the Properties of Anion Exchange Membrane (Yoshiharu Matsuda

Fuel Cells

Jiro Shiokawa

Hideo Tamura

E 115

Study on the Manufacture of Reserve Battery.

V. Study on the Cathode Materials of Aluminum

Yoshio Yokota

E121

VI. Study on the Electrolytes for Reserve Battery

Yoshio Yokota

E 129 
The Influence of Metallic Impurities in the Electrolyte

in Sodium Chloride Electrolysis by the Mercury Process.

I. Vanadium in the Presence of $\mathrm{Cr}, \mathrm{Fe}, \mathrm{Co}, \mathrm{Ni}, \mathrm{Cu}, \mathrm{Zn}$ and $\mathrm{Sn}$

II. Coexistence of Vanadium, Molybdenum, Magnesium and

Calcium Satoshi Motoo

III. Magnesium in the Presence of $\mathrm{Cr}, \mathrm{Fe}, \mathrm{Co}, \mathrm{Ni}$ and $\mathrm{Cu} \cdots\left\{\begin{array}{l}\text { Satoshi Motoo } \\ \text { Fumio Muto }\end{array}\right.$

Preparation of Lanthanum and Cerium Metal by the Fused

Salt Electrolysis

Tadashi Kuroda

Application Concerning an Improved Electrolytic Process for the

Preparation of $o, o^{\prime}$-Hydrazoanisole, $o, o^{\prime}$-Dichlorohydrazo-

benzene and $p, p^{\prime}$-Hydrazotoluene.

Kiichiro Sugino

Keijiro Odo

Taro Sekine

Kozo Shirai

Device of a Battery Employing Cation Reversible Metallic

Electrode

Eiichi Ichikawa

Electrolytic Concentration of $\mathrm{NaCl}$ Solution by Reversible

Reaction of $\mathrm{AgCl}$ Electrodes in a Concentration Cell

Studies on the Mercuric Oxide Electrode.

II. The Effects of Various Additives on the Discharge

Reaction of the Mercuric Oxide Electrode

Shiro Yoshizawa

The Decomposition Voltage of Molten Beryllium Chloride

Abstract from the Denki-Kagaku Vol. 30

Electrochemical Studies of Sodium Chlorite.

II. Corrosion of Steel in Sodium Chlorite Aqueous Solution ...Genzo Ishi

Studies on Corrosion of Metals by Viscoplastic Substances.

III. On the Mechanism of Inhibitive Action of Silicate

Compounds in Viscoplastic Substances

$\left\{\begin{array}{l}\text { Minoru Izuyama } \\ \text { Yasumasa Hayakawa }\end{array}\right.$ E 43

Fundamental Studies on Lead Contamination of the

Electro-deposited Zinc

Seitaro Fukushima

On the Azotation Reaction of Calcium Carbide Particles-

Especially on the Fluidized Azotation.

VII. Studies on the Temperature of Soft-Sintering of Calcium Cyanamide and Calcium Carbide Particles in the Course of

Azotation Reaction and Factors Involved Therein

Yuji Minemura

Yoshimasa Matsuura

Tatsuya Muto

E 43

VII. Conditions for Fluidization of Calcium

Noboru Seki

Carbide Particles in Fluidized Azotation

Yuji Minemura

Noboru Seki

E 44

IX. Studies on the Ripening Azotation of Calcium Carbide

Particles Already Subjected to Fluidized Azotation

Yuji Minemura

Kosho Shirakawa E 45

X. Studies on the Fluidized Azotation of Calcium

Isao Sato

XI. Thermal Balance of an Azotation Kiln in Which

Fluidized Azotation of Calcium Carbide Particle Are

Industrially Conducted

Yuji Minemura

Kosho Shirakawa

Yoshihiro Matsumoto 
Studies on the Electrolytic Reduction of Ketones.

III. The Electrolytic Reduction of Aliphatic Ketones

Studies on Cyclohexanone Toshio Arai

E 45 (31)

IV. The Electrolytic Reduction of Unsaturated Ketones-

Studies on Isophorone Toshio Arai

E 46 (104)

V. The Electrolytic Reduction of Aryl-alkyl Diketones-

Studies on Acetyl Benzoyl Toshio Arai

E $46(175)$

IV. The Electrolytic Reduction of Aromatic Ketones-

Studies on Fluorenone, $\alpha$-Tetralone, Acetophenone and

Benzophenone Toshio Arai

Chlorine Metallurgy of Wolfram.

I. Thermodynamic Properties of Wolfram Oxytetrachloride $\cdots\left\{\begin{array}{l}\text { Koemon Funaki } \\ \text { Kotaro Uchimura }\end{array}\right.$

II. Thermodynamic Properties of Wolfram Oxydichloride …... $\left\{\begin{array}{l}\text { Koemon Funaki } \\ \text { Kotaro Uchimura }\end{array}\right.$

III. Kineticho Uchimura

III. Kinetic Study on the Chlorination of Wolfram Oxide …... $\begin{aligned} & \text { Kataru Karasawa } \\ & \text { Woemon Funaki } \\ & \text { Koen }\end{aligned}$

IV. On the Equilibrium Wolfram Oxide and

Hydrogen Chloride Gas Koemon Funaki $\{$ Kotaro Uchimura

V. Thermodynamical Considerations on the Chlorination of Wolfram Oxide. Kotaro Uchimura

VI. Thermodynamical Considerations and Some Experiments on the Chlorination of Wolfram Minerals Koemon Funaki Kotaro Uchimura

VII. Purification of Wolfram Oxytetrachloride $\left\{\begin{array}{l}\text { Kotaro Uchimura } \\ \text { Koemon Funaki }\end{array}\right.$

Studies on the Phase Diagram of Fused Salt with Titanium Salt.

IV. Phase Diagrams of $\mathrm{K}_{2} \mathrm{TiF}_{6}-\mathrm{CaCl}_{2}, \mathrm{Na}_{2} \mathrm{TiF}_{6}-\mathrm{BaCl}_{2}$,

$\mathrm{Na}_{2} \mathrm{TiF}_{6}-\mathrm{NaF}, \mathrm{Na}_{2} \mathrm{TiF}_{6}-\mathrm{KCl}$ and $\mathrm{Na}_{2} \mathrm{TiF}_{6}-\mathrm{NaCl}-\mathrm{KCl}$ System $\ldots$ Kaoru Aotani

The Influence of Metallic Impurities in the Electrolyte in

Sodium Chloride Electrolysis by the Mercury Process.

I. Vanadium in the Presence of $\mathrm{Cr}, \mathrm{Fe}, \mathrm{Co}, \mathrm{Ni}, \mathrm{Cu}, \mathrm{Zn}$ and $\mathrm{Sn}$ Satoshi Motoo Einosuke Kobayashi

II. Coexistence of Vanadium, Molybdenum, Magnesium and Calcium Satoshi Motoo

III. Magnesium in the Presence of $\mathrm{Cr}, \mathrm{Fe}, \mathrm{Co}, \mathrm{Ni}$ and $\mathrm{Cu} \cdots\left\{\begin{array}{l}\text { Satoshi Motoo } \\ \text { Fumio Muto }\end{array}\right.$

Studies on Criteria for Cathodic Protection of Iron.

I. The Protective Potential of Mild Steel in Fresh Water...... $\left\{\begin{array}{l}\text { Hiroji Nakauchi } \\ \text { Toyoji Kobayashi } \\ \text { Haj }\end{array}\right.$

On the Behavior of Electrochemical Oxygen Analyser............... $\begin{aligned} & \text { Nagahiko Kishimoto } \\ & \text { Hiroshi Matsushita } \\ & \text { Hiroji Hironaka } \\ & \text { Taizo Nomura }\end{aligned}$

E158 (507)

The Electrolytic Reduction of Dicyandiamide

Keijiro Odo

Eiichi Ichikawa

On the Production of Persulphate by Electrolysis of Sodium

Sulphate Solution.

I. On the Formation of $\mathrm{S}_{2} \mathrm{O}_{8}{ }^{2-}$ by Electrolysis of Sodium Sulphate Solution Shiro Yoshizawa Fumio Hine Masamichi Yamashita

II. On the Production of $\mathrm{S}_{2} \mathrm{O}_{8}{ }^{2-}$ and $\mathrm{NaOH}$ by Electrolysis of Sodium Sulphate Solution

Shiro Yoshizawa 
Studies on Surface Electricity.

XIV. The Effect of Dioxane on the Adsorption Double

Layer of Surface Active Agents Shizuo Ueda Akira Watanabe

XV. On the Adsorption Behaviour of Nonionic Surface Active Agents, Considered from the Differential Double Layer Capacity (1) Shizuo Ueda Akira Watanabe

XVI. On the Adsorption Behaviour of Nonionic Surface Active Agents, Considered from the Differential Double Layer Capacity (2) Shizuo Ueda Akira Watanabe

The Transition of from Silicon Carbide from $\beta$-Form to $\alpha$-Form Sadao Yasuda

Thermodynamic Studies on Fused Ternary Alloys by

Electromotive Force Measurement

(On the Systems of $\mathrm{Zn}-\mathrm{Bi}-\mathrm{Cd}$ and $\mathrm{Zn}-\mathrm{Bi}-\mathrm{Sn}$ ) Zensaku Kozuka Jyoichiro Moriyama E162 (591)

Thermodynamic Studies on Fused Ternary Alloys by

Electromotive Force Measurement

(On the Systems of $\mathrm{Zn}-\mathrm{Pb}-\mathrm{Cd}$ and $\mathrm{Zn}-\mathrm{Pb}-\mathrm{Sn}$ ) Zensaku Kozuka Jyoichiro Moriyama E162 (663)

Thermodynamic Studies on Fused Ternary Alloys by

Electromotive Force Measurement

(On the Systems of $\mathrm{Zn}-\mathrm{Sb}-\mathrm{Cd}$ and $\mathrm{Zn}-\mathrm{Sb}-\mathrm{Sn}$ ) Zensaku Kozuka Jyoichiro Moriyama E163 (668)

Studies on Chlorination of Ti-Slag.

I. Studies on Chlorination Titanium Slags on a

Small Laboratory Scale Ken Sugimura

II. Studies on Chlorination of Titanium Slags in

an Enlarged Laboratory Scale Ken Sugimura

E164 (646)

Fundamental Studies on Sodium Amalgam Cell.

II. Polarization in Sodium Amalgam Cell. Kiyoshi Aoki Kiyoshi Nagaike

III. Output Voltage of Sodium Amalgam Cell Kiyoshi Aoki Shiro Yoshizawa

Fuel Cells.

III. Preparation of Doubly Porous Electrodes and Their Cathodic Polarization Takehiko Takahashi Kaname Ito Osamu Kawai

IV. On the Hydrogen Electrode for the High

Temperature Fuel Cell

Takehiko Takahashi Akiya Kozawa

V. On the Study of the Oxygen Electrode with

Metallic Plates.

Takehiko Takahashi Kaname Ito

VI. Two-layer Electrode of Sintered Ni-Li Oxide as Takehiko Takahashi a Fuel Cell Cathode

VII. The Concentration of Hydrogen Peroxide on the Surface of an Oxygen Electrode Kaname Ito Takehiko Takahashi

Studies on the Mechanism of Magnesium Hydroxide Precipitation.

VII. Solubility of Hydrated Magnesium Hydroxide. 
VIII. On the Impure Hydrated Magnesium Hydroxide Takayasu Shirasaki E 51 (111)

Studies on Sintered-type Alkaline Storage Batteries.

IV. Negative Plates of Sintered-type Alkaline Storage

Batteries Prepared by Fusing Salt Impregnation

Daijiro Yamashita

Yoshibumi Yamamoto E 52

Studies on Ion Exchange Membranes.

IX. Comparison of Permselectivities of Anion Exchange

Membranes for $\mathrm{NaCl}-\mathrm{Na}_{2} \mathrm{SO}_{4}$ System

Reiichi Yamane

$\left\{\begin{array}{l}\text { Yukio Mizutani } \\ \text { Yasuharu Onoue }\end{array}\right.$

E $52(94)$

X. Permselectivity of Salicylic Acid-Cation Exchange

Membranes for $\mathrm{NaCl}-\mathrm{CaCl}_{2}$ System.

Yasuharu Onoue

E 53 (189)

XI. Permselectivity of Amphoteric Ion Exchange

Membranes for $\mathrm{NaCl}-\mathrm{CaCl}_{2}$ System

Yasuharu Onoue

XII. Permselectivity of Vinylsulfonic Acid-Styrene-Cation

Exchange Membranes for $\mathrm{NaCl}-\mathrm{CaCl}_{2}$ System

Yasuharu Onoue

E104 (335)

XIII. Polarization on the Ion Exchange Membranes

Yasuharu Onoue

E 105 (415)

XX. Interpolymer Cation Exchange Membranes Prepared

Yukio Mizutani

from Polystyrenesulfonate and Polyvinylalcohol

$\left\{\begin{array}{l}\text { Yasuharu Onoue } \\ \text { Koji Motomura }\end{array}\right.$

E 106 (429)

Chemistry of Manganese Dioxide Dry Cells.

XVII. Effect of Additives on the Polarization Characteristics

and Corrosion of Zinc Anodes in Dry Cells

Taketsugu Hirai

Masataro Fukuda

E 54 (118)

XIX. Effects of Particle Size of a Manganese Dioxide

and Carbon Materials on the Chracteristics of the

Bobbins in Dry Cells

T Taketsugu Hirai

Masataro Fukuda

E199 (731) (4)

Kunio Ohashi

Takao Murakawa

E 54 (165)

Phosphoric Acid

Shigeo Nagaura

E 55 (184)

$\left\{\begin{array}{l}\text { Saburo Fukui } \\ \text { Susumu Kawan }\end{array}\right.$

Yasuo Nagae

E100 (233)

Some New Arsenate Phosphors with Lead Activator

Heisaburo Ide

Seiji Yamazaki

Studies of Hydrogen-Chlorine Fuel Cells.

I. Basic Studies of the Hydrogen-Chlorine Fuel Cell at

Low Temperature

Shiro Yoshizawa

Fumio Hine

Zenichiro Takehara

E101 (239)

Yasuhiro Kanaya

Application of Cathodic Protection to Acid Cleaning

Saburo Fukui

E101 (244)

Protective Anode Material Used During Acid Cleaning

Saburo Fukui

$\{$ Susumu Kawano

E102 (328)

Electrolytic Reduction of Uranyl Salt to Uranous Salt

Without Diaphragm

Keijiro Odo

$\{$ Eiichi Ichikawa

Kiichiro Sugino

$\mathrm{E} 106\left(\begin{array}{l}257 \\ 337\end{array}\right)$

Fundamental Consideration on the Electrical and

Masao Ando

E 107 (266)

Electrolytic Treatment of Chromic Acid Wastes Using

Cation Exchange Membrane Masatoshi Nagamatsu E 107 (325)

Studies on the Nagative Plate of Nickel Cadmium

Alkaline Batteries.

IV. The Mechanism for the Formation and the Formula of

the Primary Product Formed on a Cadmium Electrode During

the Discharge Reaction. 
V. The Infiuence of Impurities on Cadmium Plate of

Alkaline Cell Tomizo Hosono Masayoshi Matsui

E109 (417)

VI. The Effect of Impurities on the Reaction Process

During the Discharge of Cadmium Electrode

Tomizo Hosono

Masayoshi Matsui

E109 (423)

VII. The Effects of Some Impurities on the Performance

of Practical Alkaline Cell

Tomizo Hosono Masayoshi Matsui

Studies on the Mercuric Oxide Electrode.

I. Discharge Mechhanism of a Mercuric Oxide Electrode...... $\begin{aligned} & \text { Siro Yoshizawa } \\ & \text { Zenichiro Takehara }\end{aligned}$

Spectrographic Determination of Impurities in Magnesium........ $\left\{\begin{array}{l}\text { Nakaaki Oda } \\ \text { Sadayuki Tsunoo } \\ \text { Mitsuru Idohara }\end{array}\right.$

On the Glass Electrode Responsive to Sodium Ion Activity …... $\begin{aligned} & \text { Nagahiko Kishimoto } \\ & \text { Hiroshi Matsushita } \\ & \text { Hiroji Hironaka } \\ & \text { Hiroshi Maruyama }\end{aligned}$

E111 (355)

Studies on Fuel Cells.

I. Studies on the Properties of Anion Exchange

Membrane Fuel Cell.

Yoshiharu Matsuda Jiro Shiokawa Hideo Tamura

Interfacial Electrochemical Studies on Non-aqueous

Dispersions of Pigments.

I. The Effects of Water on Electrokinetic Potential

Shiro Yoshizawa

Nobuatsu Watanabe E113 (439)

The Properties of the Film Produced by Electropolishing

Aluminum Foil Zensaku Fujimura

Ionization of Molecular Hydrogen at Platinum Electrodes with

Various Surface Conditions in Alkaline Solution

Akiya Kozawa

E198 (720)

Effects of Cobalt Complex Salts on Oxygen Electrode Reaction $\cdots\left\{\begin{array}{l}\text { Kunio Ohashi } \\ \text { Kazuo Sasaki } \\ \text { Shigeo Nagaur }\end{array}\right.$

Studies on Manganese Dioxides for Dry Cells.

IV. Adsorption of water Vapor on Manganese Dioxides …..... $\left\{\begin{array}{l}\text { Shunji Ninagi } \\ \text { Yoshizo Miyake }\end{array}\right.$

Studies of the Polarization Characteristics of Activated

Carbon Electrodes by Means of a Pulse Polarizer

Jun Watanabe $\{$ Susumu Hosoi Hiroyuki Kosugi

Studies on the Mercuric Oxide Electrode.

II. The Effects of Various Additives on the Discharge

Reaction of the Mercuric Oxide Electrode

Shiro Yoshizawa

Zenichiro Takehara E200 (741)

Yasumichi Namba

Characteristics of Silver Chloride Sea Water Cells

Shiro Matsuno

Yoshio Kobayashi

E201 (748)

Electrical Characteristics of the Hydrogen-Air Fuel Cell.

I. The Relation Among the Electrical Characteristics

and the Temperature and Electrolyte Concentration

Masao Kubokawa

Saburo Makino

Hirosuke Yamazaki

E201 (752)

Studies on the Low Temperature Hydrogen-Oxygen Fuel Cells.

I. On the Hydrogen-Carbon Electrode for Fuel Cells.

Sachio Takahashi

Sunji Minagi

Yoshizo Miyake

Studies on Low-temperature Fuel Cells.

I. Electrochemical Properties of the Porous Nickel

Hydrogen Electrode in a Fuel Cell

Takuya Hata 
Studies on the High-temperature Fuel Cell.

I. Some Factors Effecting Cell Performance T Takuya Hata Kunihiko Murayama E204 (773)

Studies on Fuel Cells.

II. Electric Resistance of Cation Exchange Membranes Yoshiharu Matsuda Toshio Ishino

E204 (783)

Studies on the Hydrogen Electrodes of Ion-Exchange

Membrane Fuel Cells Hironosuke Ikeda

The Mechanism of Carburization of $\mathrm{CaWO}_{4}$ by Carbon in Vacuo Yonejiro Horiguchi Toshio Matoba

Studies on Electrode Phenomina by O.S.P. I. The Classification of Metals from Electrochemical Behavior During Deposition......Takeshiro Mine

Electromotive Force of Sodium Amalgam Cell Kiyoshi Aoki Shiro Yoshizawa Shinzo Okada Kiyomi Nagaike

Creepings of the Surface Breakdown Voltages of

Germanium P-N Junctions Takashi Kan

The Effects of Adsorbed Hydroflouric Acid on the Surface

Breakdown Voltages of High Purity Silicon P-N Junctions......Takashi Kan

On Direct Contact Gas Heating by Electrical Heating Elements ...Masao Ando

On the Accumulator Constituted of Two Reversible Electrodes,

One Reacts on Anion the Other (Metallic Plate) on

Cation Respectively Shin-ichi Furumi

X-ray Diffraction and Electron-microscopic Studies of the

Properties of Carbon Films Deposited on Ceramics Kazunori Sakurai Shinichiro Okazaki

P-N Junction on Anodic Oxide Surface of Tantalum Hajime Shiratori Tamotsu Shirogami

Studies on Removal of Silicon-compounds from $\mathrm{TiCl}_{4}$ Ken Sugimura

Preparation of Titanium Dioxide of Rutile Crystal Form from Aqueous Titanium Chloride Solution Ken Sugimura

Studies on the Thermogalvanic Corrosion.

I. Thermal Diffusion Potential in Aqueous Solution of Mixed Electrolyte Tomiya Kishi Takashi Nagai

On the Creeping Phenomenon of Selenium Photocell. I Hidenori Maezawa 